\title{
Review of recent carrying capacity models for bivalve culture and recommendations for research and management
}

\author{
Christopher W. McKindsey ${ }^{\mathrm{a}, *}$, Helmut Thetmeyer ${ }^{\mathrm{b}}$, Thomas Landry ${ }^{\mathrm{c}}$, William Silvert ${ }^{\mathrm{d}}$ \\ ${ }^{\text {a }}$ Fisheries and Oceans Canada, Institut Maurice-Lamontagne, 850 Route de la Mer, Mont-Joli, QC, Canada G5H $3 Z 4$ \\ ${ }^{\mathrm{b}}$ Leibniz Institute of Marine Sciences, Düsternbrooker Weg 20, 24105 Kiel, Germany \\ ${ }^{\mathrm{c}}$ Fisheries and Oceans Canada, Gulf Fisheries Centre, P.O. Box 5030, Moncton, NB, Canada E1C $9 B 6$ \\ ${ }^{\mathrm{d}}$ Centro de Ciências do Mar, Faculdade de Ciências do Mar e do Ambiente, Universidade do Algarve, Campus de Gambelas, \\ 8000-117 Faro, Portugal
}

Received 11 April 2006; received in revised form 29 June 2006; accepted 29 June 2006

\begin{abstract}
Models and tools for assessing the carrying capacity of an area of interest for bivalve culture can be classified according to their level of complexity and scope. In this report, we discuss and outline four hierarchical categories of carrying capacity studies: physical, production, ecological, and social carrying capacity. The assessment of carrying capacity for progressively higher categories of models is based on a sound understanding of preceding categories. We discuss each in brief and the third in more detail as this is the level at which knowledge is the most lacking and for which science may make the most advances.

(1) Physical carrying capacity may be assessed by a combination of hydrodynamic models and physical information, ideally presented and analysed within a Geographic Information System (GIS). (2) Most scientific effort to date has been directed towards modelling production carrying capacity and some of the resulting models have been used successfully to this end. Further development of these models should pay attention to (i) better modelling of feedback mechanisms between bivalve culture and the environment, (ii) a consideration of all steps in the culture process (seed collection, ongrowing, harvesting, and processing), and (iii) culture technique. (3) The modelling of ecological carrying capacity is still in its infancy. The shortcomings mentioned for models for production carrying capacity estimates are even greater for ecological carrying capacity models. GIS may be employed to consider interactions between culture activities and sensitive habitats. (4) It is recommended that social carrying capacity be evaluated only after the preceding levels have been completed so that an unbiased assessment is obtained. This however does not exclude direction from managers for scientists as to which factors (such as water clarity, specific habitats, etc.) should be evaluated. The use of expert systems to aid in management decisions is briefly discussed with a suggested application of a fuzzy expert system to this end.
\end{abstract}

(C) 2006 Elsevier B.V. All rights reserved.

Keywords: Bivalve aquaculture; Carrying capacity; Expert systems; Shellfish

\footnotetext{
* Corresponding author.

E-mail addresses: mckindseyc@dfo-mpo.gc.ca (C.W. McKindsey), hthetmeyer@ifm-geomar.de (H. Thetmeyer), landryt@dfo-mpo.gc.ca (T. Landry), bill@silvert.org (W. Silvert).
} 


\section{Contents}

1. Introduction . . . . . . . . . . . . . . . . . . . . . . . . . . . . . 452

2. Overview of "carrying capacity" categories . . . . . . . . . . . . . . . . . . . . . . . . . . 452

2.1. Physical carrying capacity . . . . . . . . . . . . . . . . . . . . . . . . . 452

2.2. Production carrying capacity. . . . . . . . . . . . . . . . . . . . . . . . . 453

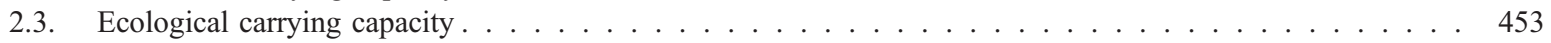

2.4. Social carrying capacity . . . . . . . . . . . . . . . . . . . . . . . . . . 454

3. Review of ecological carrying capacity . . . . . . . . . . . . . . . . . . . . . . . . 454

4. Decision framework to evaluate the carrying capacity of an area. . . . . . . . . . . . . . . . . . . 457

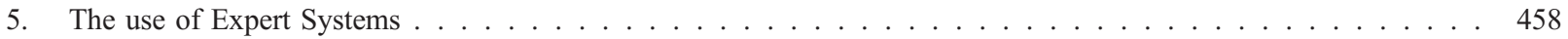

5.1. Fuzzy Expert Systems . . . . . . . . . . . . . . . . . . . . . . . . . . . . . 459

6. Knowledge gaps and research needs for ecological carrying capacity studies . . . . . . . . . . . . . . . . 460

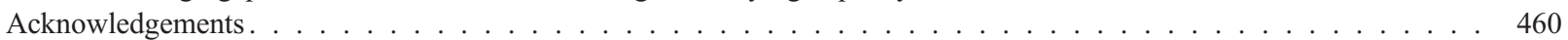

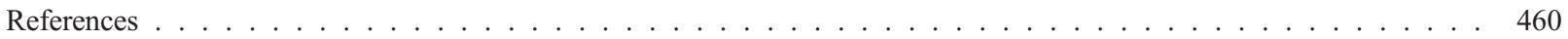

\section{Introduction}

One of the most contentious issues with respect to the development of mariculture throughout the world is the concept of "carrying capacity". Debate on this concept is often fuelled by the lack of a clear and concise definition of the term which can be interpreted on a wide scale of values that include physical, biological, and social variables. Thus, for the purpose of this discussion on carrying capacity for bivalve mariculture, we adopt the definitions of Inglis et al. (2000) who divide carrying capacity into four functional categories:

i) physical carrying capacity - the total area of marine farms that can be accommodated in the available physical space,

ii) production carrying capacity — the stocking density of bivalves at which harvests are maximized,

iii) ecological carrying capacity - the stocking or farm density which causes unacceptable ecological impacts,

iv) social carrying capacity - the level of farm development that causes unacceptable social impacts.

The objectives of this paper are to 1) give an overview of these four different categories of carrying capacity without redoing the work that has been done elsewhere, 2) give a more in-depth review and list the factors that could be considered for the determination of ecological carrying capacity as this category is the least developed in terms of predictive power, 3 ) outline a decision framework for incorporating all four categories into the determination of the overall carrying capacity of a given area for bivalve culture, and 4) outline research to address knowledge gaps for ecological carrying capacity studies.

\section{Overview of "carrying capacity" categories}

\subsection{Physical carrying capacity}

The concept of physical carrying capacity describes the area which is geographically available and physically adequate for a certain type of aquaculture. It depends on the overlap between the physical requirements of the target species and the physical properties of the area of interest (e.g., type of substrate, depth, hydrodynamics, temperature). Physical properties should also include some basic chemical variables (e.g., salinity, dissolved oxygen concentration) but not biological or organo-chemical variables (e.g., particulate organic carbon or chlorophyll concentration), which are addressed when calculating production and ecological carrying capacity. The physical carrying capacity of an area also depends on the culture technique, e.g., areas which are adequate for rope culture may not be for bottom culture and vice versa (due to bathymetric or hydrodynamic constraints).

The concept of physical carrying capacity is straightforward and may be best addressed using hydrographical models to assess areas of interest based on their physical properties and the physical (culture type) and biological requirements of the species of interest, the pertinent data being input into and analysed using Geographic Information Systems (GIS) (Congleton et al., 1999; Arnold et al., 2000; Nath et al., 2000; Pérez et al., 2002). Much of the detailed information for the various parameters needed to determine the physical carrying capacity of a given area may already be available from a variety of sources (e.g., hydrographic charts). Other more specific 
types of information (e.g., salinity in estuarine systems) may need to be gathered from field studies to ensure that conditions for growth and/or survival remain throughout the planned growing cycle, likely $>1 \mathrm{yr}$.

\subsection{Production carrying capacity}

The production carrying capacity is the optimized level of production of the target species. For filter-feeding bivalves, it will mainly depend on natural resources and is thus intimately related to the functioning of the ecosystem (e.g., Carver and Mallet, 1990; Bacher et al., 1998). Bacher et al. (2003) outline the utility of using a modelling as opposed to an experimental approach for determining the production carrying capacity of an area. Production carrying capacity may be measured, inter alia, in terms of wet or dry weight, energy or organic carbon. It greatly depends on the physical carrying capacity and the functions of the ecosystem, especially primary production within the area of interest and, at times of even more importance, the importation of organic matter. Furthermore, positive and negative feedback mechanisms between the culture activities and the ecosystem need to be considered.

Several reviews have already been done on this subject, including a series of papers published in special issues of Aquatic Ecology (volume 31(4), 1998) and the Journal of Experimental Marine Biology and Ecology (volume 219(1-2), 1998), a scoping study in Great Britain (Davies and McLeod, 2003), a couple of overviews in New Zealand (Inglis et al., 2000; Gibbs, in press) and a recent review in Canada (Chamberlain et al., 2006). The output of these reviews demonstrates that there is a wide range of modelling approaches focusing mainly on hydrodynamics, food availability and production, bivalve feeding and physiology and the influence of husbandry practices on crop production, as well as the interactions among these factors. The review by Kaiser and Beadman (2002) on production carrying capacity along with more recent developments in this field as discussed in this text suggest that, for most commercial bivalve species, the ability to assess and predict the effect of stocking densities of bivalves on their production is well developed and has been applied in a wide range of ecosystems. In general, information about the various biological parameters needed to calculate the physical carrying capacity of a targeted area (e.g., food availability) must be obtained through targeted field work. Although ideally obtained through purposespecific studies done in the targeted area, information on bivalve feeding and physiology is often taken from studies done elsewhere. The main constraint of pro- duction carrying capacity models is in their limited ability to determine feedback mechanisms, i.e., the effect of the ecosystem response to their activity. A further shortcoming on this level of modelling is that it is usually limited to the ongrowing phase and does not address the seed collection, harvesting, and processing phases. Finally, production carrying capacity will also be a function of the culture technique (e.g., bottom versus rope culture) and the geographical distribution of the culture sites in the area of interest. Gangnery et al. (2004) have started to address this problem. Using a population dynamics model they considered two methods of oyster culture (collées vs. pignes) and different rearing strategies (timing of seeding and harvesting). The primary aim of the model was to evaluate the effects of reduced growth, harvesting closure due to toxic algae blooms, and mortality of oysters due to anoxia on marketable production of oysters. Little attention has been paid to the impact of various bivalve farming activities on natural components of ecosystems. This issue is addressed in the following section on ecological carrying capacity.

\subsection{Ecological carrying capacity}

While modelling of production carrying capacity focuses on the target bivalve species and on those organisms that support its production, modelling of ecological carrying capacity should in principle consider the whole ecosystem and all culture activities from seed collection to ongrowing, harvesting and processing (Table 1). Practically, the society or their representatives have to restrict this task by defining components of interests (e.g., species or habitats) and acceptable levels of change for each of these (i.e., social carrying capacity) (Gibbs, in press). Ecological carrying capacity generally means the maximum level of production which is possible without having an unacceptable ecological impact, but it should also take into account other limiting factors such as seed availability or usable area when appropriate. Information about the potential parameters used to evaluate the components of interest may often not be available. Indeed, managers may prefer to select from among those components for which the best information is available. This may be a logical choice as such components are also likely to be among those for which society has placed a high value (and thus have been studied). A number of these parameters are described in the following section.

In contrast to production carrying capacity, there have been fewer efforts and successes in developing models to assess and predict the ecological carrying capacity of areas for bivalve culture. Also, as for production carrying 
Table 1

Selection of activities related to bivalve culture that may influence the ecological carrying capacity of a coastal area

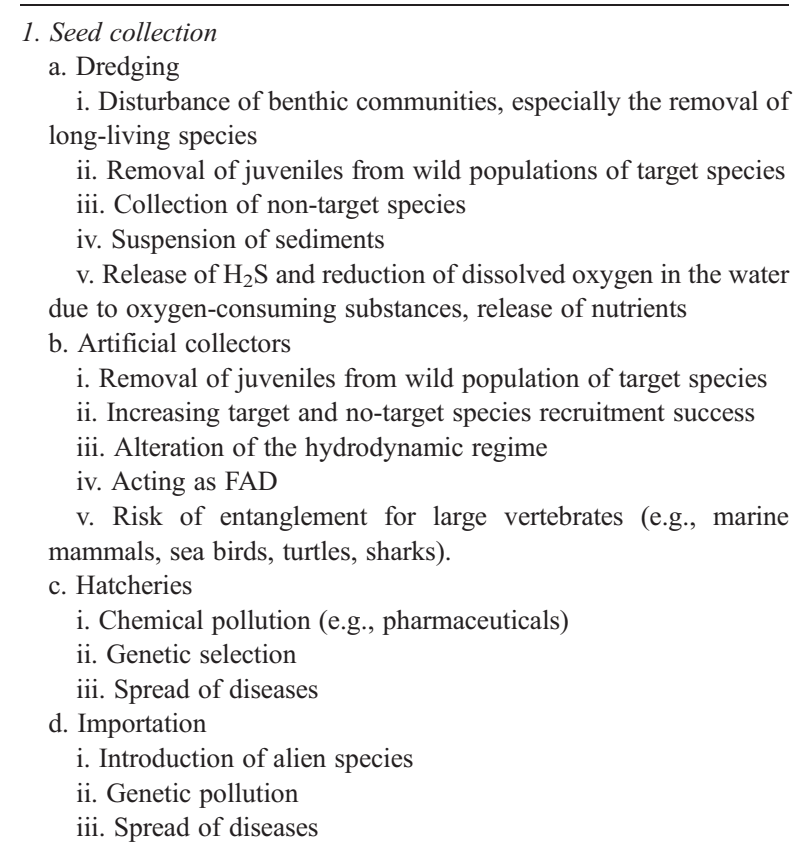

2. Ongrowing

a. Effects common to all techniques

i. Organic enrichment of seafloor

ii. Providing reef-like structures

iii. Alteration of hydrodynamic regime (current speed, turbulence)

iv. Food web effects: competition with other filter feeders, increasing recycling speed of nutrients, removal of eggs and larvae of fish and benthic organisms

v. Spawning: release of mussel larvae

vi. Providing food for predators of bivalves

vii. Control of predators and pests

b. Bottom culture

i. Activities to prepare the culture plots, e.g., dredging for predator removal

ii. Removal of associated organisms by dredging and relaying iii. Competition for space with wild benthos organisms

c. Artificial structures (trestles, poles, rafts, longlines)

i. Acting as artificial reef or FAD (attraction/displacement or enhancement of animals)

ii. Risk of entanglement for big vertebrates (e.g., marine mammals, sea birds, turtles, sharks)

\section{Harvesting}

a. Effects common to all techniques

i. Removal of biomass, nutrients

ii. Removal of non-target species

iii. Competition with predators

b. Dredging

i. Disturbance of benthos communities, especially removal of long-living species

ii. Suspension of sediments
Table 1 (continued)

3. Harvesting

iii. Release of $\mathrm{H}_{2} \mathrm{~S}$ and decrease of dissolved oxygen in the water due to oxygen-consuming substances, release of nutrients c. Collection of off-bottom structures

\section{Processing}

a. Dumping of by-catch

b. Relaying near auction houses

c. Depurating

d. Dumping of shells

e. Effluents from processing plant

f. Spread of alien species or diseases

capacity, the few attempts to develop modelling capacity in this field have been limited to the ongrowing phase of cultivation without considering all aspects of the operations and interactions with other activities from an integration perspective.

\subsection{Social carrying capacity}

The social carrying capacity is even more complex than the ecological carrying capacity. It comprises the above three categories of carrying capacity as well as tradeoffs between all stakeholders in order to meet the demands of both the population (socioeconomic factors such as traditional fisheries, employment and recreational use) and the environment (Dolmer and Frandsen, 2002; Hoagland et al., 2003; Stead et al., 2003; Gibbs, in press). Development of this category is at the heart of Integrated Coastal Zone Management (ICZM) and it must be fully developed so that responsible management decision may be made (Kaiser and Stead, 2003). Much of the information for the various pertinent parameters is often readily available. That being said, the relationships between these and other measures of carrying capacity are more nebulous, thus stressing the importance of ICZM.

\section{Review of ecological carrying capacity}

The concept of ecological carrying capacity is often driven by public perception of negative consequences of aquaculture (Stickney, 2003), which is mostly based on finfish operations. This is partly because aquaculture, especially the culture of carnivorous fish species in netpens, commonly produces elevated nutrient levels and strong organic deposition in the neighbourhood of culture sites (Cromey et al., 2000). This results from the fact that aquaculture operations, especially those in open water net farms, are leaky systems with a considerable proportion of the material added to grow the animals of 
interest ending up in the surrounding environment (Schendel et al., 2004). This addition of organic matter can overwhelm the assimilative capacity of the local environment, thus sometimes changing the physical, chemical, and biological structure of the bottom. However, high effluent levels are not limited to fish cage farms and increasing evidence shows that the culture (grow-out) of bivalves may also have considerable influences on the benthic environment (Kaiser et al., 1998). In short, bivalves growing in suspension feed on detritus, phytoand zooplankton in the water column, using part of what is filtered for growth and consolidating the remaining fraction as either faeces or pseudofaeces, which sinks relatively quickly to the bottom, potentially increasing the accumulation of organic material in the vicinity of the site. For both types of aquaculture, the "footprint" or areal size of the impact is a function of many factors, including the size and age of the farm, the species being cultivated, and local hydrodynamic and natural benthic conditions (Black, 2001; Magill et al., 2006).

To date, research on the environmental effects of aquaculture has largely focussed on benthic processes as they relate to increased deposition of organic matter (Carroll et al., 2003). Despite the evidence that aquaculture sites may influence local benthic infaunal communities (i.e., altering their structure), little work has addressed issues about their productivity and sustainability. Similarly, little research has been directed at examining interactions between bivalve aquaculture and the abundance and productivity of large benthic invertebrates, such as crabs and lobster, and fishes (Munday et al., 1994). This concentration on benthic processes also ignores the influence of bivalve culture on water-column processes and the organisms that live in association with the bivalves growing in culture. Differences on the influence of bivalve culture between benthic and pelagic components may be striking (Tenore and González, 1976). Further, most work to date has concentrated on near-field effects, ignoring far-field effects. Such effects are rarely discussed (but see Davenport et al., 2003; Gibbs, in press) and within those publications which address this issue there is a bias toward "negative" effects, largely ignoring potentially "positive" ones (see, for example, Gibbs, 2004). A more holistic approach is needed to determine the influence of bivalve aquaculture on the environment and the ecological carrying capacity of the environment for bivalve culture.

There is much scientific literature showing that the abundance of fish and macroinvertebrates is greater in areas on or immediately surrounding artificial reefs (structures placed on the bottom of the sea by humans) (Jensen, 2002) and fish aggregation devices (FADs structures positioned in the water column or at the sur- face of the water) (Castro et al., 2002), relative to areas distant to them. Aquaculture sites may function in a manner analogous to these structures (Costa-Pierce and Bridger, 2002; Olin, 2002; Davenport et al., 2003). There are many examples of wild animals benefiting from bivalve culture. For example, Tenore et al. (1982) suggested that intensive mussel aquaculture in the Ria de Arosa, Spain increases the production of fishes there, although there was no direct evidence given. This was echoed in a study by Tenore and González (1976) who found that the three-dimensional physical structure provided by the mussel culture rafts provided habitat and food resources that enhance secondary productivity in this estuary. Not surprisingly, they found that the biomass of organisms growing on mussel ropes increased with the size of the mussels and this was particularly true for suspension feeders. Other work done in the same area found increased abundances of several fish species in areas with mussel aquaculture (Chesney and Iglesias, 1979) and that the diet of numerous fish (Lopez-Jamar et al., 1984; Fernandez et al., 1995) and crab (Freire et al., 1990; Freire and González-Gurriarán, 1995) species consisted largely of epifauna from mussel lines. This is also consistent with the observation by Nelson (2003) that fishes are much more attracted to fouled FADs than clean ones. The extent to which such increases in abundances of fishes and benthic macroinvertebrates translate into a heightened productivity remains largely unknown.

Several lines of evidence suggest that an increased abundance of several species at bivalve aquaculture sites may indeed lead to an increased productivity of benthic fishes and macroinvertebrates (see McKindsey et al., 2006). Such an effect may be fairly straight forward with mussels dropping off lines supplementing the diet of foraging predators on the bottom or be manifest through cascading effects via some predatory species taking advantage of the changes in benthic community structure associated with bivalve culture.

The production of epibiota (e.g., crabs, starfish) on the mussel lines and other structures in bivalve aquaculture should also be considered in the context of determining the total productivity associated with bivalve aquaculture. The biomass and diversity of such epibiota may be substantial (Tenore and González, 1976; Carbines, 1993; Kilpatrick, 2002) and may contribute considerably to the total productivity of the site. For example, recent work by Inglis and Gust (2003) suggests that mussel farms in New Zealand may also increase not only the abundance, but also the productivity of starfish by increasing the starfish's relative growth rate and chance of successful reproduction. 
In some sense, models for calculating production carrying capacity will also contribute to determining the ecological carrying capacity of an area for bivalve culture as this will tell us at what point some of the most important filter-feeders in the system (i.e., the bivalves in culture) are having a negative feedback on themselves (and presumably other filter-feeders in the environment). Such models vary greatly in complexity from simple ratios of flushing times to filtration clearance times to simplified 2-D box models and more complex 3 -D finite element models with hydrodynamics driving the model. Simple ratio indicators include only a limited number of easily computed values (Gibbs, in press). Typical variables included in more complex models include nutrients, phytoplankton, zooplankton, the farmed species, and detritus as well as varying levels of complexity of interactions among these components (feedbacks among these variables, temperature-dependent interactions, etc) (Dowd, 2005). Still more complex models are also being developed for polyculture situations (e.g., Rawson Jr. et al., 2002; Duarte et al., 2003; Nunes et al., 2003), suggesting that this approach to develop more complex "ecosystem" models may also be useful for determining the ecological carrying capacity of areas. However, such an approach would require a better understanding of the biology of the other species to be included in the models (although useful estimates may be obtainable for related taxa). A promising method of combining biological observations with nonlinear, non-Gaussian ecosystem models using a probabilistic, or Bayesian, approach has been recently suggested to predict bivalve-environment (musselplankton-detritus) interactions and production carrying capacity for coastal areas (Dowd and Meyer, 2003).

At this time, two main classes of research are being advanced to determine the ecological carrying capacity of ecosystems for bivalve culture. The first of these uses the output from a spatially explicit hydrodynamic-dependent particle tracking models to predict (organic) flux from culture sites to the bottom. A quantitative relationship between flux and a benthic community descriptor is developed and then used to predict the influence different levels of bivalve culture on benthic community structure (Henderson et al., 2001). Although initially developed for finfish aquaculture, the DEPOMOD program (Cromey et al., 2002) has also been used to this end for mussel aquaculture in Ireland (Chamberlain, 2002), and is also being evaluated in Canada (Weise et al., 2006) and the Mediterranean (Daniele Brigolin, pers comm.). In Canada, the modelling (and validation) study is being complemented by manipulative studies to show the dose (flux)-response (community type) relationship. Manage- ment decisions regarding stocking densities will then be able to be made based on predicted (benthic) environmental outcomes.

There are a number of problems with this approach, not all of which are unique in a bivalve culture context. First, DEPOMOD has been developed for Scottish fjords, where accurate three-dimensional hydrographic models exist only in few cases. Hence, a homogenous flow field has been assumed in previous studies, i.e., that currents do not vary spatially throughout the grid (usual grid size is $1 \mathrm{~km}$ by $1 \mathrm{~km}$ ). Although this may be a reasonable assumption for comparatively small areas as encountered for point sources in finfish culture modelling, this is likely not the case for more extensive bivalve culture that may cover several square kilometres. Non-point-sources can be adequately approximated by multiple point sources. However, as for most modelling, the user must have a good understanding of the study area before beginning the modelling work.

Second, the resuspension component of DEPOMOD and any other deposition model in use has not been fully developed for bivalve aquaculture and is assumed to be static throughout the study site. Again, this may not be a reasonable assumption for extensive bivalve culture operations. The resuspension of sedimented material is complex (depends on sediment type, cohesiveness, flocculation, degradation, etc.) and likely varies both spatially and temporally. Presently, the resuspension module has been validated for Scottish fjords (salmon farms) but more studies are required to validate the current default values used in DEPOMOD (i.e., critical erosion threshold, consolidation time, etc.), especially for bivalve culture. For example, recent work by Walker et al. (2005) has shown that the critical resuspension threshold may differ markedly as the distance from culture sites increases.

Third, the default choice of the benthic community descriptor used in the model is the infaunal trophic index (ITI) (Word, 1979a,b) and there is some controversy over the validity of this index. Other more recently-developed indices (e.g., Weisberg et al., 1997; Warwick and Clarke, 1998; Borja et al., 2000; Llansó et al., 2002a; Llansó et al., 2002b; Simboura and Zenetos, 2002; Salas et al., 2004; Muxika et al., 2005) may be more appropriate and could easily be used in lieu of the ITI, although these too remain to be fully validated.

Fourth, the model has yet to be fully validated in many areas under different environmental regimes (see above) so that its applicability may not be considered to be general. Further, although this approach may be useful for a suspended culture system, its utility for bottom culture is doubtful and it does not consider other aspects of bivalve 
aquaculture that may exist, such as dredging for spat and harvesting. Finally, this approach considers only the benthic component and thus its utility in determining the ecological carrying capacity for the entire ecosystem within an area is not possible.

The second main approach that is being followed to determine ecological carrying capacity is the use of mass-balance/food web models. Early conceptual massbalance models involved examining the influence of bivalve culture as a part of the ecosystem (Tenore et al., 1982) but not as a model to predict ecological productivity capacity. More recent work has used ECOPATH (Christensen and Pauly, 1992) in order to determine the trophic functioning of areas that include bivalve culture in Chile (Wolff, 1994), Taiwan (Lin et al., 1999), South Africa (Stenton-Dozey and Shannon, 2000), Brazil (Wolff et al., 2000), and Italy (Brando et al., 2004). These models differ considerably in their complexity (i.e., number of trophic groups considered) and completeness. Predictably, the presence of bivalve culture is typically seen to promote short energy pathways with high trophic efficiency and may contribute considerably to energy cycling in the studied systems. The aim of these works, however, was not specifically to determine the ecological carrying capacities of the areas under consideration, although this was at times evaluated (e.g., Wolff, 1994). A recent paper (Jiang and Gibbs, 2005) specifically attempts to determine the carrying capacity of an area in New Zealand for bivalve culture using a mass-balance approach and the ECOPATH model. Interestingly, they found that although the production carrying capacity of the area was $310 \mathrm{t} \mathrm{yr}^{-1}$, the ecological carrying capacity of the area was only $65 \mathrm{t} \mathrm{yr}^{-1}$, above which point there would be major changes in energy fluxes within the system's food web. Future work is planned by Jeanie Stenton-Dozey (pers. comm.) to compile an ECOTROPHIC model of the Hauraki Gulf, New Zealand, to develop a sustainable fisheries and aquaculture industry in the region.

As with DEPOMOD, this approach also has limitations. First, the models used are typically steady-state and thus temporal variation in processes may not be included. Second, the mass balance model typically used (ECOPATH) is not spatially explicit. Thus the model may not be used to differentiate between near-field and far-field effects. Third, an understanding of many biological variables (life history values, interactions, etc.) is sorely lacking. Fourth, most applications of ECOPATH (with ECOSIM) do not adequately address uncertainty in data inputs and model structure (Plaganyi and Butterworth, 2004). And finally, this method, again, typically only considers the ongrowing phase of the culture; other phases need also to be studied and understood. An abridged list of the activities associated with various stages of bivalve culture that should be considered when determining carrying capacity (all types) is given in Table 1 .

In sum, most of the potential measures of ecological carrying capacity consider only a single or a restrained number of ecosystem components (Broekhuizen et al., 2002). As we learn more about the functioning of marine ecosystems it is likely that our understanding of the factors affecting ecological carrying capacity will evolve, and we need to develop a flexible approach to allow for these changes.

\section{Decision framework to evaluate the carrying capacity of an area}

We propose a hierarchical approach to determine the carrying capacity of an area for bivalve culture (Fig. 1). At the first level, the physical carrying capacity of the site is determined based on the available natural conditions and the needs of the operation and bivalves to be cultured. Second, the production carrying capacity of the available area is calculated based on modelling efforts. Third, the ecological carrying capacity of the area is estimated, again with modelling efforts, by evaluating the range of possible outcomes for production estimates varying between none (and/or the current level) and the maximum calculated as the production carrying capacity (Fig. 2). For example, scientists could use DEPOMOD to predict the spatial extent of dispersion of biodeposits from a proposed aquaculture operation at various stocking densities and configurations and predict how the benthic community would change along

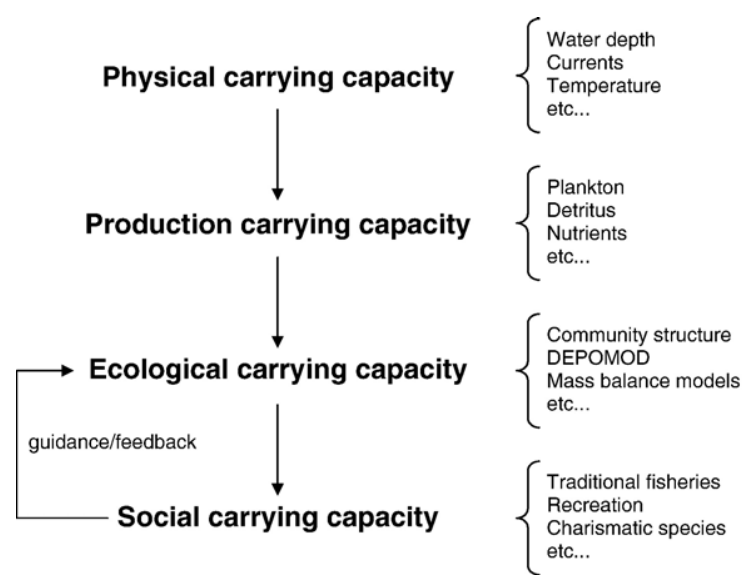

Fig. 1. Hierarchical structure to determine carrying capacity of a given area. Note that social carrying capacity feeds back directly to ecological carrying capacity to provide guidance to choose pertinent response variables to measure. 


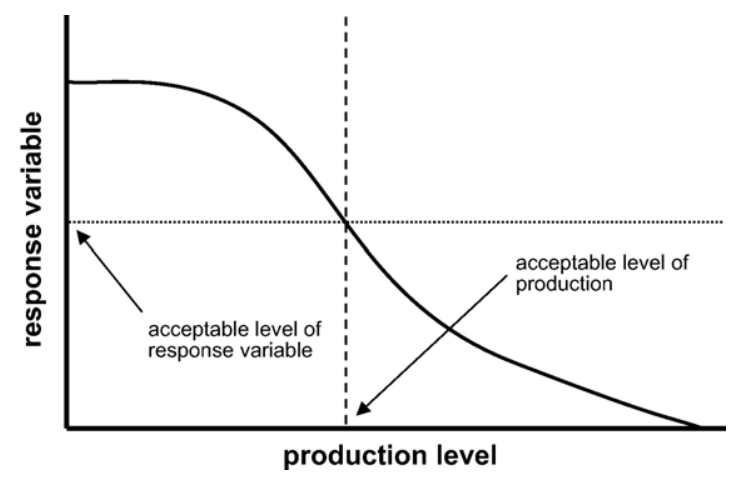

Fig. 2. Hypothetical response curve of an environmental variable under the influence of varying levels of bivalve culture production. The dotted line indicates the level of the indicator that has been determined to be acceptable by managers and the dashed line the corresponding level of production (i.e., the social carrying capacity).

potential depositional gradients. Finally, managers would weigh and balance the different scenarios based on the outcomes from each of the preceding calculations of carrying capacity and competing interests and make a decision as to what level of productivity is acceptable the social carrying capacity.

In contrast to physical and production carrying capacity, both ecological and social carrying capacity depend on social values. Thus, before being able to determine the ecological carrying capacity, the society must define environmental variables of interest (e.g., bird and fish populations, clarity of the water, eelgrass or specific rare habitats). Ideally, the ecologists/scientists in charge should then be able to select suitable tools from a tool-box (e.g., models, GIS, and comparisons with previous studies) and predict for a range of production levels scenarios regarding these variables. The society will then have to define the level of change it is willing to accept (i.e., the ecological carrying capacity). Finally, the interests of all stakeholders need to be addressed (e.g., shipping, recreation, tourism, sewage effluents, etc.), ideally within an ICZM plan, in order to assess the social carrying capacity of the management area.

It is important to note that output from the first three categories of models outlined above may or may not be available to the managers making socioeconomic-based decisions (i.e., determining the social carrying capacity) because of a paucity of scientific support and resources. Thus managers will likely have to rely on instinct, local knowledge, extrapolation from studies done elsewhere, etc. However, this does not remove the logic of the hierarchical nature of the decision tree outlined above and the process should be followed using all available information in order to derive an unbiased view of the situation and thus make appropriate management de- cisions. Failure to follow this process (by, for example, stating out of hand that certain types of development or developments in certain areas are not permitted) will likely result in otherwise feasible bivalve culture installations not being initiated. This is clearly not in the interest of effective and transparent ICZM.

\section{The use of Expert Systems}

The complexity of the decision framework and the multidisciplinary nature of the various factors that managers need to take into account pose a difficult challenge. The wide variety of factors that need to be considered poses a serious problem for effective farm siting and management. Evaluation of the four limiting types of carrying capacity — physical, production, ecological and social - requires expertise in more areas than any one person can be expected to possess. The obvious solution is to bring in experts from the different relevant fields on a regular basis to provide the best scientific advice on issues related to their specialties, but this is almost always both impractical and extremely costly. One way to resolve this problem is through the use of an "Expert System," namely the development of a library of information and tools to provide the best possible advice to decision makers even when experts in the relevant fields are not available (Silvert, 1994).

An Expert System is generally a computer package that contains a large database of information applicable to the problem at hand along with models and other programs for manipulating these data in order to provide meaningful advice to decision makers. Expert Systems are designed through consultation with experts in the field in order to provide advice similar to what the experts would advise if they were available. Expert Systems are widely used in fields like medicine, and although consulting an expert system is clearly not as satisfactory a means of diagnosing illness as examination by a skilled physician, they have great value in areas where there is a shortage of trained medical personnel.

The evaluation of aquaculture sites according to the criteria described in this report could in many respects be aided by the use of expert systems. The calculation of the physical carrying capacity relies very much on the kind of data that could be stored in a GIS, such as nutrient concentrations and bathymetry. Production carrying capacity could also be determined by combining interactive input for data such as the species to be farmed with stored data from the GIS or other database. The calculation of ecological carrying capacity relies heavily on models, and the data for these models can be extracted from the GIS and fed into a series of model 
calculations. Often the available data may not be sufficient for scientifically sound recommendations. In such cases the Expert System should indicate the lack of data and recommend adequate tools and a sampling strategy to fill the gaps.

Whether the social carrying capacity can be incorporated into an Expert System in the same way is less clear. Quite a bit of work has been done on modelling the physical, production and many ecological aspects of aquaculture, but the social aspects are qualitatively different and require their own treatment. They are not geographically as well defined, since they may involve people and institutions located some distance away (commuting workers, suppliers, markets, etc.) and the criteria are not as clearly defined. In pragmatic terms it is unlikely that a decision support system which incorporates a social model would be well accepted. Although stakeholders might accept the results of a model predicting the physical and biological consequences of a bivalve farm, they may be less likely to believe that a computer program can adequately predict their own employment prospects or trust it to demonstrate that their recreational or scenic prospects will not be adversely affected. For this reason it is probably best to focus on the physical, production and ecological carrying capacities in developing an Expert System with the idea that this would provide input to the evaluation of social carrying capacity. An Expert System could for example be used interactively at a stakeholders meeting to provide immediate answers to questions about the effects of different scenarios even though it might not be possible to have scientific experts in all areas present.

\subsection{Fuzzy Expert Systems}

One of the difficulties in applying the concepts of this report is that the carrying capacities are not precise values but are rather subject to large uncertainties. If we consider just the physical carrying capacity, defined as the total area of marine farms that can be accommodated in the available physical space, it is clear that in most cases the boundary of the suitable area is not sharply defined, and that there can be marginal areas which are not ideally suited for farm use but which are still usable. There are tradeoffs between these uncertainties, since the use of marginal areas depends on the value of the product, and if the price goes up it may be worth expanding a farm into areas which had previously been excluded from the calculation, e.g., because of physical conditions that made the installation of moorings and other structures more costly. Production carrying capacity is also not precisely defined since an expansion in production levels is likely to lead to decreased growth rates and the optimal level thus depends on market demand, interest rates and other externalities. Similarly the ecological carrying capacity is not sharply defined, since increasing the size of a farm generally causes greater environmental impact, but there are no clearly defined critical levels of benthic degradation and the impact can be reduced by remedial actions. Furthermore, since the ecological carrying capacity depends on feedback from social considerations, as described in Fig. 1, it cannot be viewed as a simple output of the system.

A better representation of how carrying capacities are determined is shown in Fig. 2, which can be interpreted as a plot of acceptability (the response variable) vs. the level of production. At very low production levels there is plenty of physical space available, the production is of course not too high, and the ecological impact is small. As we increase the level of production the physical space becomes more constrained and marginal areas are called into use, profitability is compromised, and the ecological impact increases. However, none of these reaches a sharp threshold. Furthermore there are tradeoffs, since if the product is very valuable it may be profitable to expand into marginal areas and to implement remedial measures to lessen the ecological damage. Thus the level of acceptable response shown in Fig. 2 is actually a band of response levels, and which one is most appropriate depends on other factors.

One way of addressing this is by the use of a Fuzzy Expert System, where the outputs are not precise numbers but rather functional relations between production levels and acceptability. In other words, instead of saying that the carrying capacity has some value $X$, meaning that production levels below $X$ are totally acceptable and levels above $X$ are totally unacceptable, we say that a production level of $X$ is $50 \%$ acceptable, while higher or lower values would be assigned acceptabilities of, say, $15 \%$ or $80 \%$ (Silvert, 1997, 2000). One of the immediate advantages of this is an almost automatic way of identifying tradeoffs. If we have a site where the physical carrying capacity is low but the production carrying capacity is high (possibly because of high market demand) then instead of simply saying that we have to restrict production to the low physical carrying capacity the system could identify production levels where the physical acceptability would be less than $50 \%$, perhaps $40 \%$, but the production acceptability would be high enough (say $80 \%$ ) to make up for this and to support actions which would make marginal areas profitable to develop.

One of the advantages of using a Fuzzy Expert System for evaluation of carrying capacities is the flexibility it offers and the scope for negotiation, which is a practical concern when dealing with the possibly contentious issues 
associated with the social carrying capacity. Any precise number provided for a quantity such as the physical carrying capacity is likely to generate controversy, whether it is given by a computer program or by a qualified scientist. Putting the issue in terms such as $45 \%$ rather than $55 \%$ acceptable is less likely to be a source of strong contention, since proponents or opponents of a project can argue for different production levels without having to deal with a sharp threshold whose validity can be called into question.

\section{Knowledge gaps and research needs for ecological carrying capacity studies}

In closing we suggest that the most pressing need for research with respect to determining the ecological carrying capacity for bivalve aquaculture includes the following subjects:

- Studies must be done to better understand the environmental interactions (positive and negative) of various types of bivalve culture including all farming activities from seed collection to ongrowing, harvesting and processing. All farming activities need to be considered in models and Geographic Information Systems.

- Existing models must be made spatially explicit.

- Temporal variation must be built into existing models, this is especially true with respect to harvesting and other seasonal activities.

- Models must be validated in a number of locations to evaluate their generality.

- Appropriate management tools, such as Fuzzy Expert Systems, must be developed to aid in decision making.

\section{Acknowledgements}

The core of this paper was developed during the 2005 ICES Working Group on Environmental Interactions of Mariculture (WGEIM) workshop that was held in Ottawa, Canada, in April 2005. A previous version appeared in the proceedings of that workshop (http://www.ices.dk/reports/MCC/2005/WGEIM05. pdf). Thanks go to the WGEIM and Jon Chamberlain for reviewing earlier versions of this paper.

\section{References}

Arnold, W.S., White, M.W., Norris, H.A., Berrigan, M.E., 2000. Hard clam (Mercenaria spp.) aquaculture in Florida, USA: geographic information system applications to lease site selection. Aquac. Eng. 23, 203-231.

Bacher, C., Duarte, P., Ferreira, J.G., Heral, M., Raillard, O., 1998. Assessment and comparison of the Marennes-Oleron Bay (France) and Carlingford Lough (Ireland) carrying capacity with ecosystem models. Aquat. Ecol. 31, 379-394.

Bacher, C., Grant, J., Hawkins, A.J.S., Fang, J., Zhu, M., Besnard, M., 2003. Modelling the effect of food depletion on scallop growth in Sungo Bay (China). Aquat. Living Resour. 16, 10-24.

Black, K.D., 2001. Environmental Impacts of Aquaculture. CRC Press, Boca Raton. 214 pp.

Borja, A., Franco, J., Pérez, V., 2000. A marine biotic index to establish the ecological quality of soft-bottom benthos within European estuarine and coastal environments. Mar. Pollut. Bull. 40, 1100-1114.

Brando, V.E., Ceccarelli, R., Libralato, S., Ravagnan, G., 2004. Assessment of environmental management effects in a shallow water basin using mass-balance models. Ecol. Model. 172, 213-232.

Broekhuizen, N., Zeldis, J., Stephens, S.A., Oldman, J.W., Ross, A.H., Ren, J., James, M.R., 2002. Factors Related to the Sustainability of Shellfish Aquaculture Operations in the Firth of Thames: a Preliminary Analysis. Hamilton, New Zealand. NIWA Client Report EVW02243: vi+106 p.

Carbines, G.D., 1993. The Ecology and Early Life History of Notolabrus celidotus (Pisces: Labridae) Around Mussel Farms in the Marlborough Sounds, Zoology. University of Canterbury, Christchurch. pp. 134.

Carroll, M.L., Cochrane, S., Fieler, R., Velvin, R., White, P., 2003. Organic enrichment of sediments from salmon farming in Norway: environmental factors, management practices, and monitoring techniques. Aquaculture 226, 165-180.

Carver, C.E.A., Mallet, A.L., 1990. Estimating the carrying capacity of a coastal inlet for mussel culture. Aquaculture 88, 39-53.

Castro, J.J., Santiago, J.A., Santana-Ortega, A.T., 2002. A general theory on fish aggregation to floating objects: an alternative to the meeting point hypothesis. Rev. Fish Biol. Fish. 11, 255-277.

Chamberlain, J., 2002. Modelling the Environmental Impacts of Suspended Mussel (Mytilus edulis L.) Farming. Napier University, Edinburgh. pp. 200.

Chamberlain, J., Weise, A.M., Grant, J., Dowd, M., 2006. Modeling Approaches to Assess the Potential Effects of Shellfish Aquaculture on the Marine Environment. DFO Can. Sci. Advis. Sec. Res. Doc. 2006/032: iv +50 p.

Chesney Jr., E.J., Iglesias, J., 1979. Seasonal distribution, abundance and diversity of demersal fishes in the inner Ria de Arosa, northwest Spain. Estuar. Coast. Mar. Sci. 8, 227-239.

Christensen, V., Pauly, D., 1992. ECOPATH II - a software for balancing steady-state ecosystem models and calculating network characteristics. Ecol. Model. 61, 169-185.

Congleton, W.R., Pearce, B.R., Parker, M.R., Beal, B.F., 1999. Mariculture siting: a GIS description of intertidal areas. Ecol. Model. 116, 63-75.

Costa-Pierce, B.A., Bridger, C.J., 2002. The role of marine aquaculture facilities as habitats and ecosystems. In: Stickney, R.R., McVey, J.P. (Eds.), Responsible Marine Aquaculture. CABI Publishing, Wallingford, pp. 105-144.

Cromey, C.J., Nickell, T.D., Black, K.D., 2000. DEPOMOD Software for Predicting Deposition of Wastes Arising From Fish Farms. NERC Link Aquaculture project: $10 \mathrm{p}$.

Cromey, C.J., Nickell, T.D., Black, K.D., 2002. DEPOMOD modelling the deposition and biological effects of waste solids from marine cage farms. Aquaculture 214, 211-239.

Davenport, J., Black, K., Burnell, G., Cross, T., Culloty, S., Ekarante, S., Furness, B., Mulcahy, M., Thetmeyer, H., 2003. Aquaculture: the Ecological Issues. Blackwell Publishing, Oxford. 89 pp. 
Davies, I.M., McLeod, D., 2003. Scoping Study for Research into the Aquaculture (Shellfish) Carrying Capacity of GB Coastal Waters. $109 \mathrm{p}$.

Dolmer, P., Frandsen, R.P., 2002. Evaluation of the Danish mussel fishery: suggestions for an ecosystem management approach. Helgol. Mar. Res. 56, 13-20.

Dowd, M., 2005. A bio-physical coastal ecosystem model for assessing environmental effects of marine bivalve aquaculture. Ecol. Model. 183, 323-346.

Dowd, M., Meyer, R., 2003. A Bayesian approach to the ecosystem inverse problem. Ecol. Model. 168, 39-55.

Duarte, P., Meneses, R., Hawkins, A.J.S., Zhu, M., Fang, J., Grant, J., 2003. Mathematical modelling to assess the carrying capacity for multi-species culture within coastal waters. Ecol. Model. 168, 109-143.

Fernandez, L., Freire, J.L., Gonzalez-Gurriaran, E., 1995. Diel feeding activity of demersal fishes in the Ria de Arousa (Galicia, NW Spain): an area of intense mussel raft culture. Cah. Biol. Mar. 36, $141-151$.

Freire, J., González-Gurriarán, E., 1995. Feeding ecology of the velvet swimming crab Necora puber in mussel raft areas of the Ría de Arousa (Galicia, NW Spain). Mar. Ecol., Prog. Ser. 119, $139-154$.

Freire, J., Fernández, L., González-Gurriarán, E., 1990. Influence of mussel raft culture on the diet of Liocarcinus arcuatus (Leach) (Brachyura: Portunidae) in the Ría de Arousa (Galicia, NW Spain). J. Shellfish Res. 9, 45-57.

Gangnery, A., Bacher, C., Buestel, D., 2004. Modelling oyster population dynamics in a Mediterranean coastal lagoon (Thau, France): sensitivity of marketable production to environmental conditions. Aquaculture 230, 323-347.

Gibbs, M.T., 2004. Interactions between bivalve shellfish farms and fishery resources. Aquaculture 240, 267-296.

Gibbs, M.T., in press. Sustainability performance indicators for suspended bivalve aquaculture activities. Ecol. Indic.

Henderson, A., Gamito, S., Karakassis, I., Pederson, P., Smaal, A., 2001. Use of hydrodynamic and benthic models for managing environmental impacts of marine aquaculture. J. Appl. Ichthyol. 17, $163-172$.

Hoagland, P., Jin, D., Kite-Powell, H., 2003. The optimal allocation of ocean space: aquaculture and wild-harvest fisheries. Mar. Res. Econom. 18, 129-147.

Inglis, G.J., Gust, N., 2003. Potential indirect effects of shellfish culture on the reproductive success of benthic predators. J. Appl. Ecol. 40, 1077-1089.

Inglis, G.J., Hayden, B.J., Ross, A.H., 2000. An Overview of Factors Affecting the Carrying Capacity of Coastal Embayments for Mussel Culture. NIWA, Christchurch. Client Report CHC00/69: vi+31 p.

Jensen, A., 2002. Artificial reefs in Europe: perspective and future. ICES J. Mar. Sci. 59, S3-S13.

Jiang, W.M., Gibbs, M.T., 2005. Predicting the carrying capacity of bivalve shellfish culture using a steady, linear food web model. Aquaculture 244, 171-185.

Kaiser, M.J., Beadman, H.A., 2002. Scoping study of the carrying capacity for bivalve cultivation in the coastal waters of Great Britain. The Crown Estate. Interim Report: 39 p.

Kaiser, M., Stead, S.M., 2003. Uncertainties and values in European aquaculture: communication, management and policy issues in times of "changing public perceptions". Aquacult. Int. 10, 469-490.

Kaiser, M.J., Laing, I., Utting, S.D., Burnell, G.M., 1998. Environmental impacts of bivalve mariculture. J. Shellfish Res. 17, 59-66.
Kilpatrick, B.D., 2002. Assessing Habitat Value of Modified Rack and Bag Aquaculture Gear in Comparison With Submerged Aquatic Vegetation and a Non-Vegetated Seabed. University of Rhode Island, Providence. pp. xii +157.

Lin, H.J., Shao, K.T., Kuo, S.R., Hsieh, H.L., Wong, S.L., Chen, I.M., Lo, W.T., Hung, J.J., 1999. A trophic model of a sandy barrier lagoon at Chiku in southwestern Taiwan. Estuar. Coast. Shelf Sci. 48, 575-588.

Llansó, R.J., Scott, D.B., Dauer, D.M., Hyland, J.L., Russell, D.E., 2002a. An estuarine benthic index of biotic integrity for the midAtlantic region of the United States. I. Classification of assemblages and habitat definition. Estuaries 25, 1219-1230.

Llansó, R.J., Scott, D.B., Hyland, J.L., Dauer, D.M., Russell, D.E., Kutz, F.W., 2002b. An estuarine benthic index of biotic integrity for the mid-Atlantic region of the United States. II. Index development. Estuaries 25, 1231-1242.

Lopez-Jamar, E., Iglesias, J., Otero, J.J., 1984. Contribution of infauna and mussel-raft epifauna to demersal fish diets. Mar. Ecol., Prog. Ser. $15,13-18$.

Magill, S.H., Thetmeyer, H., Cromey, C.J., 2006. Settling velocity of faecal pellets of gilthead sea bream (Sparus aurata L.) and sea bass (Dicentrarchus labrax L.) and sensitivity analysis using measured data in deposition model. Aquaculture 251, 295-305.

McKindsey, C.W., Anderson, M.R., Barnes, P., Courtenay, S., Landry, T., Skinner, M., 2006. Effects of shellfish aquaculture on fish habitat. DFO Can. Sci. Advis. Sec. Res. Doc. 2006/011: viii $+84 \mathrm{p}$.

Munday, B., Eleftiheriou, M., Kentouri, M., Divanach, P., 1994. Quantitative statistical analysis of the literature concerning the interaction of the environment and aquaculture - identification of gaps and lacks. J. Appl. Ichthyol. 10, 319-325.

Muxika, I., Borja, A., Bonne, W., 2005. The suitability of the marine biotic index (AMBI) to new impact sources along European coasts. Ecol. Ind. 5, 19-31.

Nath, S.S., Bolte, J.P., Ross, L.G., Aguilar-Manjarrez, J., 2000. Applications of geographical information systems (GIS) for spatial decision support in aquaculture. Aquacult. Eng. 23, 233-278.

Nelson, P.A., 2003. Marine fish assemblages associated with fish aggregating devices (FADs): effects of fish removal, FAD size, fouling communities, and prior recruits. Fish. Bull. 101, 835-850.

Nunes, J.P., Ferreira, J.G., Gazeau, F., Lencart-Silva, J., Zhang, X.L., Zhu, M.Y., Fang, J.G., 2003. A model for sustainable management of shellfish polyculture in coastal bays. Aquaculture 219, 257-277.

Olin, P.G., 2002. Environmental interactions of bivalve shellfish aquaculture. In: Tomasso, J.R. (Ed.), Aquaculture and the Environment in the United States. U.S. Aquaculture Society, Baton Rouge, pp. 141-154.

Pérez, O.M., Telfer, T.C., Beveridge, M.C.M., Ross, L.G., 2002. Geographical Information Systems (GIS) as a simple tool to aid modelling of particulate waste distribution at marine fish cage sites. Estuar. Coast. Shelf Sci. 54, 761-768.

Plaganyi, E.E., Butterworth, D.S., 2004. A critical look at the potential of ECOPATH with ECOSIM to assist in practical fisheries management. S. Afr. J. Mar. Sci. 26, 261-287.

Rawson Jr., M.V., Chu, C., Ji, R., Zhu, M., Wang, D., Wang, L., Yarnish, C., Sullivan, J.B., Chopin, T., Carmona, R., 2002. Understanding the interaction of extractive and fed aquaculture using ecosystem modelling. In: Stickney, R.R., McVey, J.P. (Eds.), Responsible Marine Aquaculture. CABI Publishing, Wallingford, pp. 263-296.

Salas, F., Neto, J.M., Borja, A., Marques, J.C., 2004. Evaluation of the applicability of a marine biotic index to characterize the status of 
estuarine ecosystems: the case of Mondego Estuary (Portugal). Ecol. Ind. 4, 215-225.

Schendel, E.K., Nordstrom, S.E., Lavkulich, L.M., 2004. Floc and sediment properties and their environmental distribution from a marine fish farm. Aquac. Res. 35, 483-493.

Silvert, W., 1994. Putting management models on the manager's desktop. J. Biol. Syst. 2, 519-527.

Silvert, W., 1997. Ecological impact classification with fuzzy sets. Ecol. Model. 96, 1-10.

Silvert, W., 2000. Fuzzy indices of environmental conditions. Ecol. Model. 130, 111-119.

Simboura, N., Zenetos, A., 2002. Benthic indicators to use in ecological quality classification of Mediterranean soft bottom marine ecosystems, including a new biotic index. Med. Mar. Sci. 3/2, 77-111

Stead, S.M., Burnell, G., Goulletquer, P., 2003. Aquaculture and its role in Integrated Coastal Zone Management. Aquacult. Int. 10, $447-468$

Stenton-Dozey, J.M.E., Shannon, L.A., 2000. Impact of mariculture on ecosytems: an ECOPATH approach to assess the impact of mussel culture on trophic interactions, 1st MARICULT Conference. Trondheim, Norway.

Stickney, R.R., 2003. How did we get into this mess? Junk science vs. real science. World Aquacult. 34 (4-7), 71.

Tenore, K.R., González, N., 1976. Food chain patterns in the Ria de Arosa, Spain: an area of intense mussel aquaculture. In: Persoone, G., Jaspers, E. (Eds.), Proceedings of the 10th European Symposium on Marine Biology, Ostend, Belgium, September 17-23, 1975. Population Dynamics of Marine Organisms in Relation with Nutrient Cycling in Shallow Waters, vol. 2. Universa Press, Wetteren, pp. 601-619.

Tenore, K.R., Boyer, L.F., Cal, R.M., Corral, J., Garcia-Fernandez, C., Gonzalez, N., Gonzalez-Gurriaran, E., Hanson, R.B., Iglesias, J., Krom, M., Lopez-Jamar, E., McClain, J., Pamatmat, M.M., Perez, A., Rhoads, D.C., de Santiago, G., Tietjen, J., Westrich,
J., Windom, H.L., 1982. Coastal upwelling in the Rias Bajas, NW Spain: contrasting the benthic regimes of the Rias de Arosa and de Muros. J. Mar. Res. 40, 701-772.

Walker, T.R., Grant, J., Hill, P.S., Cranford, P., Lintern, G., Scofield, B., 2005. Measuring particle dynamics in Arctic and mussel aquaculture environments, 12th Canadian Coastal Conference, Dartmouth, NS, pp. $1-11$.

Warwick, R.M., Clarke, K.R., 1998. Taxonomic distinctness and environmental assessment. J. Appl. Ecol. 35, 532-543.

Weisberg, S.B., Ranasinghe, J.A., Dauer, D.M., Schaffner, L.C., Diaz, R.J., Frithsen, J.B., 1997. An estuarine benthic index of biotic integrity (B-IBI) for Chesapeake Bay. Estuaries 20, 149-158.

Weise, A.M., McKindsey, C.W., Archambault, P., Callier, M.D., 2006. Modelling the biodeposition and environmental effects of suspended mussel (Mytilus edulis) aquaculture in Eastern Canada: Adapting Depomod to shellfish aquaculture. In: Johnson, L.E., Cusson, M. (Eds.), 35th Benthic Ecology Meeting, Quebec City, QC, pp. 28-29.

Wolff, M., 1994. A trophic model of Tongoy Bay — a system exposed to suspended scallop culture (Northern Chile). J. Exp. Mar. Biol. Ecol. 182, 149-168.

Wolff, M., Koch, V., Isaac, V., 2000. A trophic flow model of the Caeté Mangrove Estuary (North Brazil) with considerations for the sustainable use of its resources. Estuar. Coast. Shelf Sci. 50, 789-803.

Word, J.Q., 1979a. The infaunal trophic index. In: Bascom, W. (Ed.), Southern California Coastal Water Research Project, Annual Report (1979). SCCWRP, Los Angeles, pp. 19-39.

Word, J.Q., 1979b. The infaunal index. A relative abundance measure of the benthic infauna and how it may be applied to fish food habits studies. In: Lipovsky, S.J., Simenstad, C.A. (Eds.), Presented at: 2. Pacific Northwest Technical Workshop, Gutshop '78; Maple Valley, WA (USA); 10 Oct 1978, pp. 37-42. 